\title{
Paideusis
}

\section{Rigorous Standards, At What Price? Or What Will Students Learn When No One is Looking?}

\section{Barbara Applebaum}

Volume 14, Number 1, 2001

URI: https://id.erudit.org/iderudit/1072822ar

DOI: https://doi.org/10.7202/1072822ar

See table of contents

Publisher(s)

Canadian Philosophy of Education Society

ISSN

0838-4517 (print)

1916-0348 (digital)

Explore this journal

Cite this article

Applebaum, B. (2001). Rigorous Standards, At What Price? Or What Will Students Learn When No One is Looking? Paideusis, 14(1), 15-29.

https://doi.org/10.7202/1072822ar viewed online.

https://apropos.erudit.org/en/users/policy-on-use/ 


\section{Rigorous Standards, At What Price? \\ Or What Will Students Learn When No One Is Looking?}

\section{Barbara Applebaum, Ontario Institute for Studies in Education of the University of Toronto}

\section{Introduction}

Over the past two decades, educational reform in the United States and in Canada has been dominated by a burgeoning discourse around the concept of standards. Acknowledging that "standards" play a vital role in the achievement of excellence in education, this essay aims to examine the meaning and use of "standards" in the context of contemporary educational reform in the United States. An implicit understanding of standards as fixed criteria, it is argued, has driven such reform and the excessive reliance being placed on standardized tests as the sole determinant of promotion or graduation in many cities across the United States seems to support this claim. Standards as fixed criteria are specific behavioral outcomes on the basis of which what a student knows and can do at a particular time and place is evaluated. Standards as fixed criteria, however, are ill equipped to measure certain habits of mind that may be important educational goals. Thus, it is argued desirable educational attitudes and dispositions may be undervalued or ignored. In addition, standards as fixed criteria, it is contended, encourage an unwarranted confidence in regards to the ends of education and inhibit democratic dialogue on the issue of what those ends should be.

As an alternative to standards as fixed criteria, standards as ideals are proposed to direct educational reform. Standards as ideals are general statements about educational aspirations that guide teachers' attempts to get their students closer to the ideal. Although standards as ideals have an assessment function, they are not fixed or rigid measurements, nor are rewards or punishments their purpose. Such a notion of standards encourages an openness towards diverse points of view regarding the ends of education. In addition, the notion of standards as ideals fosters the recognition that education is not only about producing possessors of bits of knowledge but is also about educating persons. As the discourse on educational standards in Canada continues to evolve, Canadian educators, educational administrators and educational theorists are advised to clarify the conception of standards that grounds their platform of reform. This essay hopes to alert Canadian educators to the costs of an implicit reliance on standards as fixed criteria and to recommend that they consider a conception of standards as ideals to guide 
educational reform.

In his critique of national educational standards, Elliot Eisner ${ }^{1}$ enumerates three conceptions of standards - standard as a typical level of performance, standard as a value, and standard as a unit of measure. Standards, in the first sense, focus on what is typical in the sense of a mediocre level of evaluation, as when we say the meal was a standard meal. Here "standard" is used as a descriptor and always implies mediocrity. In the second sense, a standard refers to a value, principle or ideal that "people have cared enough about to die for."2 The standards that people strive for will often reflect who they are and what is important to them. Finally, a standard can also be a unit of measure by which the quality of a product is assessed or by which the suitability of something or someone to do a particular job is evaluated. Like standards as unit of measure, standard as mediocrity alludes to evaluation. However, standards as a unit of measure focus more on the functional suitability of something or someone given a particular end or need. Standards as units of measure are yardsticks or criteria of assessment, and depend on the purpose or need for measurement. Thus, standards as units of measure differ significantly from the use of "standard" to describe a typical or mediocre quality. For example, standards as units of measure may apply high standards to evaluate food quality, depending on the reason or need for assessment.

Indeed, these various conceptions of standards are not unrelated. Standards as values or ideals often implicitly function as units of measure in that we often evaluate certain things by the value or ideal they consummate. One may deem one's life to be worthy, for example, because it was an honest one and honesty is an ideal one strives for. Standards as units of measure, in addition, can be set at typical or mediocre levels of performance as when we set standards for the qualification of certain jobs at the minimum proficiency level necessary to perform the job.

Standards understood as units of measure, Eisner contends, implicitly gird most of the contemporary academic literatures around educational reform in the United States. The two other conceptions of standards, Eisner argues, do not ground current educational initiatives in the United States,

Surely we do not mean by standards a typical level of performance, since that is what we already have without an iota of intervention. As for standards that represent beliefs or values, we already have mission statements and position papers in abundance. ${ }^{3}$

When educational reformers advocate standards-based initiatives, standards as units of measure, although not explicitly acknowledged, are implied. This is congruent with the value United States society places on technology and the quantification of performance as a means to objective assessment. Standards in education are to be 
objective, quantifiable means by which we can evaluate a student's performance relative to a measurable ideal. By objective, advocates of standards are not necessarily implying that the content of standards are somehow context and culturally neutral (although some advocates of standards may so believe). Rather, the focus on objectivity falls primarily on the process of assessment, the ways in which we can measure a student's performance relative to the standard. Indeed, advocates of standards-based reform believe that it is important to develop uniform tests by which we can compare students to other students, schools to other schools, districts to other districts across the nation and world, and at any point in time.

While standardized testing may have a useful function, the astounding emphasis being currently placed upon such assessment in the United States lends support to the contention that standards as units of measure are the linchpins of such reform. In the United States today, standardized tests are increasingly becoming the exclusive yardsticks by which students are judged "educated" as is intimated in the commonly heard phrase "high-stakes testing". Twenty-seven states require high school students to pass a standardized test in order to graduate, according to Monty Neill, executive director of the National Center for Fair \& Open Testing, and four other states require students to pass standardized tests as a condition for promotion from one grade to another. ${ }^{4}$ Across the nation, decisions are being made about a student's life based on one test and some cities like Chicago and New York report that students are dropping out rather than having to fail the new high-stakes tests needed for a diploma. ${ }^{5}$ Most of those who opt for dropping out are low-income and minority students. Moreover, even school funding recently has been tied to average school scores on standardized tests.

\section{Standards as Fixed Criteria}

When standards are understood as units of measure and are reflected in a heavy emphasis on standardized testing, assumptions about effective learning are concealed. Standards as units of measure assume that learning is behavioural and can be quantitatively measured. Effort is comprehended to be the key to learning and, thus, the problem with schools is that they are just too easy. Advocates of standards-based educational reform in the United States, Deborah Meier explains, assume that

[C]lear-cut expectations, accompanied by automatic rewards and punishments, will produce greater effort, and effort - whether induced by the desire for rewards, fear of punishment, or shame - is the key to learning. ${ }^{6}$

When standards as units of measure guide educational reform, standards become fixed as rigid criteria that become embodied in the form of standardized testing and 
are assumed all we need to cure the crisis in education. Standardized testing further assume a "one size fits all" mentality and is primarily concerned with what a student knows and can do at a particular time and place. This understanding of standards forms the basis for much of current educational reform in the United States and will be referred to as standards as fixed criteria.

Standards as fixed criteria focus primarily on what a student has to achieve in terms of skills and content in order to be certified as "educated". They refer to technical and rigidly fixed criteria that take the form of standardized test. Standards as fixed criteria are primarily backward-looking conditions in that they are supposed to retroactively measure what has already been taught. At the same time, advocates of educational reform maintain that standards as fixed criteria can also function as forward-looking stimuli believed to motivate teachers and students to reach certain goals. ${ }^{8}$ This is problematic and dangerous, especially when the type of motivation such an understanding of standards fosters, as will be discussed subsequently, is disregarded.

Yet, even in its backward-looking function "standards as fixed criteria" may be counterproductive to the achievement of certain educational goals. Not everything we want our students to attain in school, as Eisner points out, can be measured in this fashion. Although standards as rigid criteria can be effectively used to measure such skills as spelling correctly and basic math and language skills, they are not applicable for all we want to teach our students. Creativity or the innovation required in higher order thinking, for example, is a valuable educational goal, yet whose outcomes cannot be measured by standardized testing. Such goals require fluid expectations, not rigidly fixed, technical standards of criteria. Because such educational goals cannot be measured by standardized testing, advocates of standards-based educational reform tend to give them short shrift. ${ }^{9}$ In other words, when standards are understood as fixed criteria and are driven by standardized tests, important aims of education may fall by the wayside. Even if advocates of standards-based reform do not devalue these important educational goals, the forward-looking use of such standards will not help their students to achieve such goals. In other words, applying the framework of fixed criteria measured by tests that externally reward and punish to certain educational goals impedes not facilitates educators' ability to help students achieve certain goals.

Certain desirable educational goals such as creativity or critical thinking are not episodic abilities or one-time performances. In his discussion of critical thinking as an educational goal, Harvey Siegel argues that the critical thinker is one who is "appropriately moved by reasons". This implies that it is not enough to develop in 
our students the requisite skills and abilities to evaluate reasons and arguments, what Siegel refers to as the reason assessment component of critical thinking. In addition, the critical thinker must also possess a certain disposition or habits of mind that Siegel refers to as "the critical spirit".

It is not enough that a person be able to assess reasons properly; to be a critical thinker she must actually engage in competent reason assessment, and be generally disposed to do so. She must habitually seek reasons on which to base belief and action, and she must genuinely base belief, judgment, and action on such reasons. She must, that is, be appropriately moved by reasons; given that there are compelling reasons to believe, judge or act in a certain way, the critical thinker must be moved by such reasons to so believe, judge, or act. She must, that is, have habits of mind which make routine the search for reasons; she must, moreover, be disposed to base belief, judgment, and action on reasons and the warrant they provide. $^{10}$

According to Siegel, the critical thinker is not someone who just knows and is able to do critical thinking. The critical thinker is a certain kind of person; someone who is moved by reasons. Not only are standards as criteria ineffectual in measuring this, standards as criteria, as will soon be argued, may also hinder the development of such kinds of persons.

Clearly, it would be difficult to claim that a student is a critical thinker, for example, because he/she demonstrates critical thinking in a number of answers on a one time, high-stakes standardized test. Standards perceived as fixed criteria can only measure fixed skills and knowledge but not the attitudes, dispositions and character-traits that are commonly believed to be essential elements of the educated person. Linda Nathan ${ }^{11}$ similarly argues that what the standards movement cannot value are the "habits of mind" that we, as educators, want to develop in our students. Yet, these habits of mind are extremely important. Whether advocates of educational reform based on standards as fixed criteria actually believe these dispositions are peripheral to education or whether because these dispositions are beyond the reach of standardized tests, they become peripheral is not clear. Nevertheless, the point remains that these important educational goals become lost in the vortex of "teaching to the test".

Education is involved in developing certain kinds of people and is not only about what our students know and are able to do. Robert Coles tells us, "I remember my father talking at the dinner table about character, telling my brother and me, when we were young, that 'character is how you behave when no one is looking'." 12 Rather than doing away with the notion of standards, what we need is a conception of standards that will foster the habits of mind that can motivate our 
students to learn even when no one is looking and that will encourage the development of a love for learning. Yet standards understood as fixed criteria and driven by standardized tests may actually thwart the development of certain character traits that are considered educational aims.

What do students learn about learning when standards as fixed criteria are exceedingly emphasized? Will the type of education implied by current educational reforms encourage students to learn anything outside the classroom setting? Or will students get the message that learning is arduous and not joyful, as some critics of standards-based reform such as Susan Ohanian, Deborah Meier and Alfie Kohn contend?

In her discussion of the call for "rigorous standards", Susan Ohanian ${ }^{13}$ argues that the "standardistos" (those who advocate standard-based educational reform) are always trying to prove "my standards are tougher than yours." Indeed, Deborah Meier bewails the standardized tests in Massachusetts in which fourth graders are required to know "anything that happened between prehistoric times and A.D. 500 in 'the world' and in the United States until 1865."14 Alfie Kohn maintains that when advocates of the standards-based reform movement demand more rigorous standards what they really mean is tougher standards, i.e., learning requiring more work and more effort. This effort is supposed to improve the educational situation in the United States. Yet, as Kohn so articulately reminds us, this is to confuse harder with better. Kohn contends,

Underlying the kind of pedagogy and assessment associated with the tougherstandards movement is an assumption that has rarely been identified and analyzed namely, that the main thing wrong with the schools today is that kids get off too easy. Texts and tests and teaching have been "dumbed down", it is alleged. At the heart of metaphors like raising standards (or the bar) is the premise that harder is better. ... (Yet) to judge schools by how demanding they are is rather like judging an opera on the basis of how many notes it contains that are hard for singers to hit. In other words, it leaves out most of what matters. ${ }^{15}$

Kohn does not deny the importance of sustained attention and effort, however, he underscores that being hard to do, in itself, is not always a sign that something is better. Rather that being concerned only with creating onerous work for our students, Kohn argues, we should be more concerned with creating challenging work. "Don't we want students to be 'challenged' more, or to live up to 'higher expectations' in a school that stands for excellence?"16 The type of challenge that advocates of standards-based educational reform promote has more to do with just coercing students to meet "an academic requirement that a cross section of successful adults in the community cannot." 17 The standards that are 
guiding educational reform, according to Kohn, are "not merely unreasonable but irrelevant". ${ }^{18}$ In addition, such standards may have deleterious effects, a point that is implicit in the following comic of a father speaking to his son who is doing his homework.

Adam: Still having trouble with that math problem?

Son: Uh huh.

Adam: Here, lemme have a crack at it.

Son: Good luck.

Adam (perplexed as he bends over in concentration trying to solve the math problem) Hmm... (straightens upright) Are you sure this is part of your regular homework and not punishment for something bad you did at school that you're not telling me about?

Son: Honest. ${ }^{19}$

When we pay close attention to this comic, it becomes apparent that what makes it funny is not that the parent does not know what his child is learning in school. Rather, the sad "humor" lies in that both parent and child associate rigorous learning with punishment!

When I was a middle school teacher a number of years ago, it always amazed me when my students would bring in something to talk about in class that is relevant but "outside of the curriculum" and then ask me if I will give them "extra credit' for their efforts. When standards are consistently understood as fixed criteria and coupled with high-stakes tests, it is not surprising that students get the message that learning is onerous work and requires external rewards. Indeed, a possible consequence of such an approach to education is that learning becomes associated with punishment and can only be roused with external incentives. It further troubles me tremendously when many of my students who scored high on the vocabulary part of the mandated standardized test do not go to a dictionary when they come across a word that they do not understand in a book or newspaper.

This is not to imply that the teaching of content is unimportant. Rather, it is to claim that to make content knowledge the primary function of education is to assume that our aim in education is just to create great Jeopardy players. Albert Einstein, after having won the Nobel Prize in physics, was asked what the speed of light was. Einstein, in his great humility, honestly exclaimed that he did not know. "But you are the smartest man in the world," the inquisitor exclaimed, "how is it that you don't know this fact?" Einstein replied, "It's no big deal because if I ever need to know it, I know where I can look it up." Part of Einstein's genius was not in his ability to memorize facts and regurgitate them but in his love for learning, for his creative ability to see things in different ways. When we love to learn, we may 
not remember all the details but we will know where to look them up when we need them. Yet, if learning is only an onerous task, we may know all the facts in the world but as Whitehead put it, they will just be "inert ideas". ${ }^{20}$ When one possess the habits of a good learner, however, "the learning of content makes so much more sense." Indeed, it is important to ask that our educational reforms be concerned with what our students will learn even when no one is looking.

\section{Standards as Ideals}

Eisner proposes an alternative to the concept standards when he introduces the distinction between standards and goals. While the former function as specific behavioral outcomes by which we judge our students, the latter involve general statements about aspirations or guidelines that "enable one to search more efficiently for the qualities that might matter in any individual work". ${ }^{22}$ To judge all of what we do in education by standards as units of measure, or by what I have referred to as fixed criteria, "colors our view of what education can be and dilutes our conception of education's potential.". ${ }^{23}$ Although Eisner recommends we use the language of goals instead of standards, I maintain that we can retain the discourse of standards using a conception of standards as ideals. In order to develop the ways in which standards as ideals could better facilitate educational reform, it is important to first elaborate what standards as ideals are.

In his discussion of the role that ideals should play in teaching, David Hansen describes ideals as pointing to

territory beyond the familiar, the known, the previously attainable. They embody possibilities which the human spirit can generate. Even though they may be out of reach, ideals can provide a source of guidance and courage. ${ }^{24}$

Hansen maintains that when teachers have ideals that they are striving for, they do not need "a tap on the shoulder" to do what they should be doing. When a teacher is experiencing difficulty with a particular student, it is the teacher's ideals, more than rewards and punishments, that will motivate him/her to continue with his/her pedagogical efforts. In addition, Hansen argues, when a student falls short of the ideal, the ideal guides the teacher in developing short term goals which will help him/her move the student closer to the ideal. Although Hansen acknowledges the problems and possible limitations of ideals in teaching, ${ }^{25}$ he maintains that the guidance and inspiration that ideals afford cannot be ignored in teacher education.

Hansen's discussion about ideals in education helps to explicate the meaning of standards as ideals. Ideals are not rigid endpoints but sources of insight and "... the ideal is there not as unattainable perfection but to inform the present, to underline what we must attend to, and to help in locating what obstructs the 
realization of the ideal."26 An ideal functions as an image that both motivates and guides the teacher. "She assists a student struggling with reading while holding onto an image of the student as a successful reader. That image strengthens her resolve and fuels her energy."27 Standards as ideals are forward-looking aspirations rather than backward-looking units of measure. Standards as ideals cannot be rigid and fixed endpoints. Rather, more accurately, standards as ideals are direction-pointers, telling educators where they need to go. Since they are forward-looking, they still have an assessment function. Yet, their assessment function has nothing to do with external rewards and punishments of action. ${ }^{28}$. Although standards as ideals can help us to evaluate where a student is in terms of his/her educational achievement, the purpose of standards as ideals when used for assessment is only to assist teachers in understanding how they can get their students closer to the ideal. When standards are understood as ideals, they focus on challenging students so that they come closer to the ideal and thus, promote, rather than impede, the development of life long learning. Learning is valued as an ideal and is not only a means for something else. Learning, in other words, becomes an end in itself.

Standards as ideals are more appropriate for educational reform than standards as fixed criteria. While the latter delineate a single vision to guide our schools and thus, minimize or ignore diversity, ${ }^{29}$ the former, by preventing the reification of content, keep us ever vigilant and open to diverse points of view. Standards as fixed criteria conceal the need to inquire "what are these standards for?" As William Ayers contends, assumptions about the goals of education must be publicly out in the open and constantly exposed to debate in democratic forums. Ayers writes,

I'm all for clarity of standards, for a more explicit sense of what we expect from students. The questions, however, are: What do we value? What knowledge and experience are of most worth? ... Who decides? These kinds of deep and dynamic questions are never entirely summed up, never finished; they are forever open to the demands of the new. ... Standards setting should be part of the everyday vocation of schools and communities, the heart and soul of education, and it should engage the widest public. Standards setting means systematically examining and then reexaming what we care about, what we hope for, what the known demand of us next. $^{30}$

When our conception of standards is exclusively focused on fixed criteria, this democratic revisioning all but gets lost. A close examination of a groundbreaking legal case in Canada ${ }^{31}$ can help illustrate how difficult but important it is to constantly ask, "what are our standards for?"

In 1995, and after 3 years of being a competent firefighter, Tawney Meiorin 
lost her job because she failed to pass an aerobics test. The required test was the outcome of a set of standards developed for firefighters by the province of British Columbia. Although Meiorin passed three of the four physical tests required to keep her job, she missed the 11 minute cutoff for the two-and-a-half kilometer run by 49.4 seconds. Meiorin sued the Government of British Columbia claiming that the cutoff time for the test was biased against women because it was determined solely on the basis of men's physical capabilities.

The popular press was replete with cries of foulplay. Meiorin was pulling out the "gender card" in self-seeking ways. The test is fair, as many of her critics claimed, because "the faster the better". Is it not just common sense that the more aerobics ability a firefighter has the better? Only those people who are the "fittest" should be firefighters.

In a surprising and unanimous decision, however, the Supreme Court of Canada ruled against what was thought to be "common sense". Although the province apparently developed its aerobics test in good faith, it failed to properly consider the different physiology of males and females. The province of British Columbia was guilty of creating its test standards based primarily upon a sample of elite male firefighters, without paying any heed to the aerobic capacity of women. Not only was the province's standards created with only men in mind but also the resulting standard showed no evidence of being an essential qualification for being a good forest firefighter. Madam Justice Beverly McLachlin ruled that the prescribed aerobic capacity was not necessary for either men or women to perform the work of a forest firefighter satisfactorily. The type of work that Meiorin was assigned to do required that she had the requisite knowledge, not that she be able to outrun a fire.

In this important decision, the court brought it to the public's attention how easy it is for employers to develop stringent standards that may not even be essential for doing the job and may, however unintentionally, discriminate against certain groups of people. Any test or standard must be rationally connected to its objective. It must be reasonably necessary in order to accomplish a valid purpose.

Some important insights can be gleaned from this Canadian case regarding the meaning and the use of standards as a means of school-based reform. First of all, in clarifying what a standard is, the Canadian case highlights that standards are socially constructed mediums by which we can gauge the required level of quality or proficiency for something or someone to be called the thing that the standard stands for. Tawney Meiorin had to satisfy the standards determined by the province of British Columbia in order to be a qualified firefighter. Students have to satisfy the standards determined by the appropriate experts in order to be qualified as an 
"educated person".

To say that standards are socially constructed, does not imply that any standard will do. But it does help to point out that standards are not valuable in themselves; they are inherently connected to the idea or ideal they are thought to measure. Running two and half kilometers in itself in not something anyone need to be able to do. It is a standard because it reflects what a group of experts think a firefighter should be able to do. Standards are only valuable in that they are reflections of some idea or ideal. In this case, the ideal was what it means to be a competent firefighter; in the case of our students, the ideal of what it means to be an educated person.

In the case of the firefighters, reflecting upon average proficiency sets standards. In the Meiorin case, the two-and-a-half kilometer run was a standard that was set by reflecting upon the average proficiency of an elite group of men who were good firefighters but it ignored the average proficiency of women who were also good firefighters. Thus, standards can be set in a fair manner, but they may also be (often, unintentionally) set in ways that are biased and that create and reproduce injustice. In the area of education, the questions that the debate over standards must raise are:

- On the grounds of whose "average proficiency" are standards derived?

- Who decides what educational aims should be?

This is not to imply that rigorous standards are not important but rather to remind us that standards should not become reified to the point where we no longer can see what standards are for and also what harms they can do.

To return once more to our Canadian example, an unacknowledged partiality towards a particular group of people blinded those who established the standard in terms of their ability to recognize discrimination and injustice. Those who created the standard for firefighters had a conception of the average male firefighter in their mind when they established the standard. Meiorin accused this male-biased standard of being an arbitrary limit rather than a capacity indispensable to being a good forest firefighter. Those in the public media who proclaimed "faster is always better" had no conception of what is needed to be a good firefighter; those who so quickly accused Meiorin of playing the "gender card" did not believe it was necessary to ask. These people seemed to have had a conception of standards as fixed criteria. Judge McLachin, on the other hand, could be said to have understood standards as ideal and, thus, she was able to question the relationship between the standard and what it was intended to measure.

Just as Judge McLachin's ruling did not imply that all the standards 
developed for judging the qualification of a firefighter are similarly discriminatory, I am not implying that all standards are discriminatory and harmful. I am suggesting, however, that we must be continually vigilant how standards are set and what standards are for.

\section{Conclusion}

Across Canada, provincial educational reform is placing strong emphasis on rigorous standards and provincial standardized testing. ${ }^{32}$ In Ontario, for example, standardized tests are recognized to be only one component of the provincial government's plan to improve the quality of education. Other elements include:

- a more rigorous curriculum,

- a code of conduct concerned with creating a safe environment for students to learn and for teachers to teach,

- regulations to ensure that parents have a stronger voice in their children's education and

- a teacher testing program so that teachers sustain a high level of skill..$^{33}$ Moreover, the Ontario government, in its news releases, indicates a theoretical recognition of the limits of simple quantitative measures and that testing for real understanding must be done in conjunction with classroom teachers. The dangers of over-emphasizing standardized testing, however, always hovers close by as the media and parents misinterpret the value of individual and average school test scores. Thus, clarification around the concept of standards that grounds Canadian educational reform is important.

Moreover, as Portelli and Vibert, two of the few Canadian educational theorists who dare to criticize common educational standards, remind us, educational standards are not absolute, fixed, naturally-given facts but rather are socially constructed and in constant need of being challenged and revised.

And we need to ask who constructed these standards, for what reasons, and whose values are included and excluded from them. The public discussion on standards will continue to reproduce inequities and injustices unless these questions are dealt with seriously and differences are recognized. ${ }^{34}$

Portelli and Vibert advocate an open-mindedness, although not a total relativism, regarding the debate about standards in the Canadian context as a necessary condition of Canada's commitment to democracy.

It has been the contention of this paper that standards as ideals rather than a conception of standards as fixed criteria is more amenable to the aims of education as espoused by the provincial governments. Grounding any standards-based reform movement on the conception of standards as ideals encourages educators, 
educational administrators, educational theorists, as well as parents and legislators to ask "What will our students learn when no one is looking?" as well as, "What are standards for?"

\section{Notes}

1. Elliot Eisner, “Standards for Schools: Help or Hindrance?" In W. Hare and J. Portelli, eds., Philosophy of Education: Introductory Readings, second edition (Alberta, Calgary: Detselig, 1996).

2. Ibid., 333

3. Ibid., 333

4. USA Today (Friday, June 11, 1999) 10A.

5. USA Today (Monday, May 8, 2000) 18A, Editorial.

6. Deborah Meier, "Educating a Democracy." In D. Meier, ed., Will Standards Save Public Education? (Boston: Beacon Press, 2000) 9 (italics mine).

7. Susan Ohanian, “One Size Fits Few." Rethinking Schools vol. 13, no. 4 (Summer 1999).

8. As Louise Gerstner, the chief executive officer of IBM and a strong proponent of standards based educational reform, wrote in the New York Times, "We must establish clear goals and measure progress to them. We must articulate exactly what we expect from schools, teachers, principles, students, and parents, and we must provide rewards and incentives to reach them...If the goals are not met we need to enact stiff penalties...All of this will require...testing and assessment..." (Quoted in Harold Berlak, "Standards and the Control of Knowledge." Rethinking Schools, 13/3, Spring, 1999, www.rethinkingschools. org/Archives/13_03/control.html.) Also note Albert Shanker's, (former) president of the American Federation of Teacher and a member of the National Board of Professional Teaching Standards, comment, "...the purpose of these standards is essentially to motivate all of your youngsters to work harder to reach whatever is the next highest goal..." (Interview with Ben Wattenberg, "Think Tank" see transcript www.pbs.org/ thinktank/archive/transcript. 125.html.)

9. This is not to imply that advocates of standards based educational reform do not value such educational goals as critical thinking. Rather, my contention is that if what is taught in the classroom is dependent upon what can be measured by standardized tests, the likelihood that the habits of mind associated with critical thinking will be de-emphasized is increased. A larger, related question can be raised, the discussion of which is beyond the scope of this paper. Are the criticisms of educational reform that relies heavily on standards as fixed criteria and discussed in this paper a product of differing and competing conceptions of education? Or, are those who propose such educational reform defeating their own aims? 10. Harvey Siegel, "That Old-Time Enlightenment Metanarrative: Rationality as an Educational Ideal." In Rationality Redeemed? Further Dialogues on an Educational Ideal (New York: Routledge, 1997) 3.

11. Linda Nathan, "Habits of Mind." In D. Meier, ed., Will Standards Save Public Education (Boston: Beacon Press, 2000) 50-56. 
12. Robert Coles, The Call of Stories: Teaching and the Moral Imagination (Boston: Houghton Mifflin, 1989) 198.

13. Susan Ohanian, "One Size Fits Few."

14. Deborah Meier, "Educating a Democracy." 7

15. Alfie Kohn, "Confusing Harder with Better." Education Week vol. 19, no.2 (Sept. 15, 1999) 68 and 52 (Commentary) (italics mine).

16. Ibid.

17. Ibid.

18. Ibid.

19. “Adam @ Home”, Brian Basset, 18 Feb., 1999.

20. Alfred North Whitehead, The Aims of Education and Other Essays (New York: Macmillan, 1929).

21. Linda Nathan, "Habits of Mind" 53.

22. Eisner, "Standards for School", 339.

23. Ibid. 340-341.

24. David Hansen, "The Place of Ideals in Teaching." Philosophy of Education Society 2000 (Urbana: Philosophy of Education Society, in press).

25. For example, Hansen acknowledges that ideals can develop a momentum of their own, and may end up being followed uncritically. Consequently, there is a tendency for people to end up treating ideals as more important than actual human beings, to prefer the ideal to the real.

26. Harriet K Cuffaro, Experimenting with the World: John Dewey and the Early Childhood Classroom (New York: Teachers College Press, 1995) 100, as cited by Hansen.

27. David Hansen, "The Place of Ideals in Teaching."

28. Among alternative methods of assessment that are not as problematic as high-stakes standardized tests and that do not have a tendency to appear overly punitive are portfolios and performance exams. The primary purpose of these alternative methods of assessment is to provide information that can help the student improve his/her learning.

29. Harold Berlak, "Standards and the Control of Knowledge."

30. William Ayers, "The Standards Fraud." In D. Meier, ed., Will Standards Save Public Education (Boston: Beacon Press, 2000) 65.

31. The Globe and Mail (Friday, September 10, 1999) A1-2.

32. See Government of Manitoba, www.edu.gov.mb.ca/mtks4/curricul/assess/aeoverview/

overvew2.html; see Government of British Columbia, www.bced.gov.bc.ca/exams/; also see Learner Assessment - Alberta Learning, www.loearning.gove.ab.ca/k_12/testing/ achievement/bulletins/ach_standards.html.

33. Ontario Ministry of Education News Release, January 11, 2001 (http://mettowas21.edu. gov.on.ca/eng/document/nr/01.00/nr0111.html).

34. John P. Portelli and Ann Vibert, "Dare We Criticize Common Educational Standards?" McGill Journal of Education/ Revue Des Sciences De L'Education De McGill, (Vol. 32, no. 1, Winter, 1999) p. 75. 


\section{Author}

Barbara Applebaum is currently a Visiting Scholar at the Ontario Institute for Studies in Education of the University of Toronto. Her area of research interest is to be found at the point where ethics, education and commitments to diversity converge. Barbara's most recent project involves explicating a situated moral agency and its implications for education. 